\title{
SIFAT ISOLATOR PANAS PAPAN SEKAM PADI DENGAN VARIASI RESIN DAN UKURAN PARTIKEL
}

\author{
${ }^{1}$ Sri Handani, ${ }^{1}$ Iwan Aprion, ${ }^{1}$ Sri Mulyadi dan ${ }^{2}$ Elvis Adril \\ ${ }^{1}$ Jurusan Fisika FMIPA Universitas Andalas \\ ${ }^{2}$ Politeknik Padang \\ shandani69@yahoo.com
}

\begin{abstract}
ABSTRAK
Telah dilakukan penghitungan konduktivitas panas $(k)$ untuk mengetahui sifat isolator panas dari papan sekam padi dengan metode plat rangkap. Papan sekam padi dibuat dengan variasi diameter sekam dan kadar resin. Sekam padi setelah digiling divariasikan menjadi tiga kelompok ukuran, yaitu sekam berdiameter kecil dari $1 \mathrm{~mm}$, di antara $1 \mathrm{~mm}$ hingga $2 \mathrm{~mm}$ dan lebih besar dari $2 \mathrm{~mm}$. Kadar resin divariasikan menjadi tiga kelompok, yaitu $\pm 20 \%, \pm 45 \%$ dan $\pm 75 \%$. Hasil penelitian menunjukkan bahwa harga konduktivitas panas masing-masing sampel papan sekam sangat kecil dan bervariasi. Papan sekam padi yang mempunyai harga konduktivitas panas yang paling rendah atau memiliki sifat isolator panas paling tinggi adalah papan sekam padi dengan diameter sekam kecil dari $1 \mathrm{~mm}$ dan kadar resin $\pm 20 \%$ dengan $k=0,187\left(\mathrm{~J} \mathrm{~s}^{-1} \mathrm{~m}^{-1} \mathrm{~K}^{-1}\right)$, sedangkan papan sekam padi yang mempunyai harga konduktivitas panas yang paling tinggi atau sifat isolator paling rendah adalah papan sekam padi yang diameter sekamnya lebih besar dari 2 mm dan kadar resin $\pm 75 \%$ dengan konduktivitas panas $k=0,329\left(\mathrm{~J} \mathrm{~s}^{-1} \mathrm{~m}^{-1} \mathrm{~K}^{-1}\right)$.
\end{abstract}

Kata Kunci : Konduktivitas panas, diameter sekam, kadar resin, densitas papan, metode plat rangkap

\section{PENDAHULUAN}

Sekam merupakan hasil sampingan dari proses penggilingan padi. Dari proses penggilingan biasanya diperoleh sekam sekitar $20-30 \%$, dedak antara 8- 12\% dan beras giling antara 50-63,5\% data bobot awal gabah (Deptan., 2009). Sekam padi selama ini dikenal sebagai limbah yang selalu dibakar oleh petani setelah proses penggilingan, sehingga seringkali menimbulkan polusi udara terhadap lingkungan di sekitar. Untuk menanggulangi hal itu, perlu adanya alternatif untuk dapat didayagunakannya limbah sekam padi sehingga mengurangi efek polusi yang ditimbulkannya.

Sekam padi telah banyak dimanfaatkan sebagai bahan untuk melindungi es dari suhu lingkungan, dengan mengisolasi es agar tidak cepat mencair. Sekam padi dijadikan sebagai bahan tambahan untuk meningkatkan kualitas genteng (Jolianingsih, 2004), sebagai bahan pembuatan silika amorf (Harsono, 2002) dan sebagai isolator panas (Wibowo, dkk., 2007)

Dalam pemanfaatan sekam padi sebagai isolator panas, sekam padi diolah menjadi papan. Untuk mengolah sekam padi menjadi papan, sekam padi dicampur dengan bahan pengikat berupa resin. Papan pertikel tersebut kemudian diuji unjuk kerjanya dalam hal kemampuan menahan kalor dengan menghitung konduktivitas panasnya.

\section{METODE PENELITIAN}

Bahan yang digunakan adalah sekam padi dan resin. Sekam padi dan resin dibuat menjadi papan dengan variasi ukuran sekam dan kadar resin yang berbeda. Sekam yang sudah digiling dibedakan menjadi 3 ukuran, yaitu yang berdiameter kecil dari $1 \mathrm{~mm}$, 
berdiameter 1 hingga $2 \mathrm{~mm}$ dan berdiameter besar dari $2 \mathrm{~mm}$. Variasi persen berat resin yang digunakan adalah $\pm 20 \%, \pm 45 \%$ dan $\pm 75 \%$.

Pengujian dilakukan dengan metode plat rangkap dua. Pengujian dilakukan untuk mencari tipe sampel yang memiliki sifat isolator yang baik dengan melihat nilai konduktivitasnya. Semakin kecil nilai konduktivitas suatu bahan maka akan semakin baik sifat isolator panasnya. Sifat isolator suatu bahan menggambarkan seberapa baik bahan tersebut dapat menahan laju aliran panas.

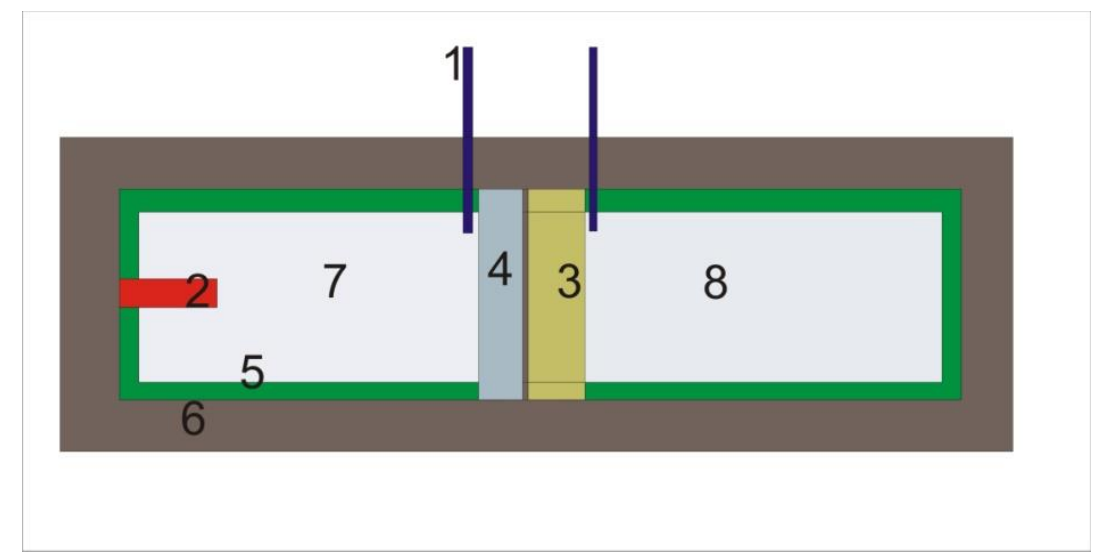

Gambar 1. Skema kotak pengujian konduktivitas panas

Keterangan gambar :

1. Biru

2. Merah

3. Kuning

4. Abu-abu

5. Hijau

6. Coklat

7. Ruang A

8. Ruang B
: termometer/ termokopel

: elemen pemanas sebagai sumber kalor

: papan sekam

: aluminium

: lapisan gabus kotak terisolasi

: lapisan kayu kotak terisolasi

: ruang isolasi sumber panas

: ruang Isolasi

Dinding kotak terbuat dari 2 buah lapisan, yaitu lapisan kayu di bagian luar dan lapisan gabus di bagian dalam. Sumber panas yang digunakan merupakan pemanas dengan daya 80 watt. Sebagai pengukur temperatur digunakan termometer digital yang memiliki kemampuan membaca temperatur sampai $250{ }^{\circ} \mathrm{C}$.

Pengujian isolator panas dilakukan pada sembilan buah sampel dengan karakteristik yang berbeda-beda. Pada pengujian ini, diukur temperatur kedua sisi permukaan plat. Sampel digandengkan dengan plat aluminium. Tujuannya agar temperatur yang terbaca mendekati temperatur yang sebenarnya.

Sampel dipanaskan dengan mengalirkan kalor dari sumber kalor untuk menciptakan perbedaan temperatur pada kedua sisi permukaan bahan sehingga kalor akan mengalir dari sisi yang bertemperatur tinggi ke sisi yang bertemperatur rendah. Dinding kotak dibuat terisolasi untuk menjamin tidak ada kalor yang masuk atau keluar ke lingkungan. Pada kedua sisi dipasang alat ukur temperatur, untuk membaca perubahan temperatur $(\Delta \mathrm{T})$, laju aliran kalor $\Delta \mathrm{Q}$, gradien temperatur $\Delta \mathrm{T}$, luas plat $\mathrm{A}$, dan ketebalan plat diukur $(L)$. Energi listrik $\Delta \mathrm{W}$ yang diserap pemanas selama interval waktu $\Delta \mathrm{t}$ sebanding dengan kuantitas kalor yang mengalir pada sampel selama selang waktu tertentu. Bila diasumsikan tidak ada kehilangan energi, maka kuantitas yang diperoleh digunakan untuk menghitung konduktivitas panas $k$ sampel dengan persamaan : 


$$
k=\frac{\Delta W}{\Delta t} \frac{L}{A \Delta T}
$$

Sebagai variabel bebas dalam penelitian ini adalah densitas dan ukuran partikel papan sekam, lalu dilihat pengaruh variabel tersebut terhadap nilai konduktivitas bahan. Selain itu, pengaruh resin juga menjadi perhatian dalam penelitian ini. Nilai selisih temperatur $\left(\mathrm{T}_{\mathrm{a}}-\mathrm{T}_{\mathrm{b}}\right)$ digunakan untuk menghitung nilai konduktivitas panas $\quad(k)$ dari papan sekam dengan menggunakan Persamaan ( 1 ) dan dengan mengganti bahan yang pertama dengan aluminium dan bahan kedua dengan papan sekam, maka Persamaan ( 1 ) menjadi :

$$
k=\frac{L_{\text {sekam }}}{\frac{A\left(T_{a}-T_{b}\right)}{H}-\frac{L_{\text {plat }}}{k_{\text {plat }}}}
$$

dengan, $\quad H=$ laju perpindahan kalor $(\mathrm{J} / \mathrm{s})$

$$
\begin{aligned}
& H=\frac{\Delta W}{\Delta t}=\text { Daya pemanas (Watt) } \\
& L \quad=\text { ketebalan }(\mathrm{m}) \\
& A \quad=\text { luas permukaan }\left(\mathrm{m}^{2}\right) \\
& T_{a} T_{b} \quad=\text { temperatur dinding plat }(\mathrm{K}) \\
& k_{\text {plat }} \quad=\text { konduktivitas panas plat aluminium }\left(\mathrm{Js}^{-1} \mathrm{~m}^{-1} \mathrm{~K}^{-1}\right)
\end{aligned}
$$

\section{HASIL DAN PEMBAHASAN}

Pada penelitian ini, sekam padi divariasikan menjadi 3 kelompok berdasarkan diameter partikelnya, yaitu sekam dengan diameter kecil dari $1 \mathrm{~mm}, 1$ hingga $2 \mathrm{~mm}$ dan besar dari $2 \mathrm{~mm}$. Masing-masing ukuran dikombinasikan dengan variasi kadar resin yang berbeda seperti pada Tabel 1 .

Pada Tabel 1 terlihat adanya perbedaan warna pada tiap-tiap sampel. Warna hitam pada sampel terjadi karena resin yang dipakai adalah damar atau perekat yang biasa digunakan oleh nelayan dalam mendempul perahu. Resin ini memiliki warna dasar hitam sehingga papan akan makin hitam apabila kadar resin dibuat makin tinggi. Resin ini dipakai karena memiliki daya rekat yang baik, ekonomis dan tahan terhadap air. Selanjutnya akan dilihat pengaruh kadar resin tersebut terhadap nilai konduktivitas papan sekam. 
Tabel 1 Tampilan papan sekam dengan ukuran dan kadar resin yang berbeda

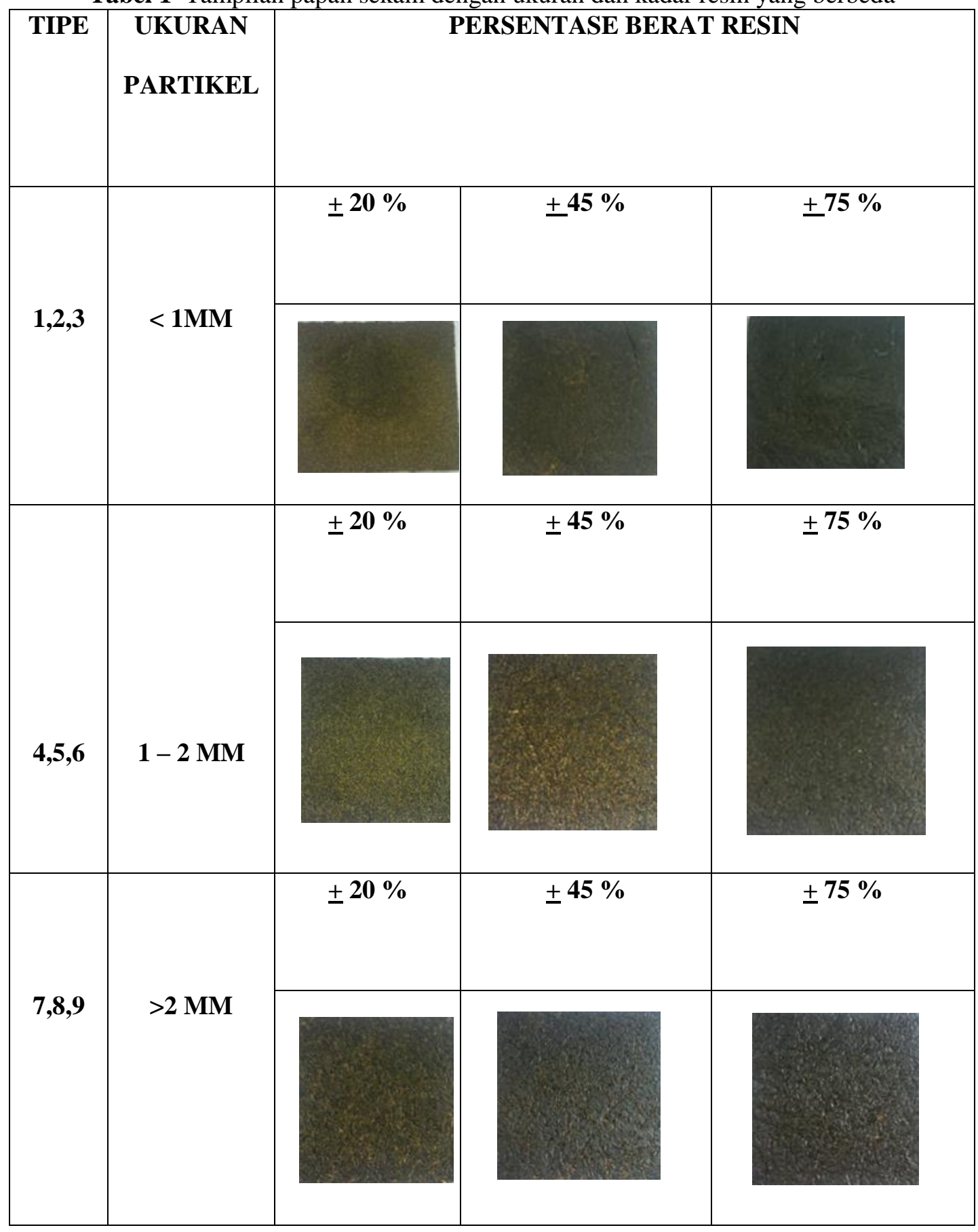

Nilai konduktivitas panas papan untuk tiap-tiap ukuran sekam ditunjukkan oleh Gambar 2. 


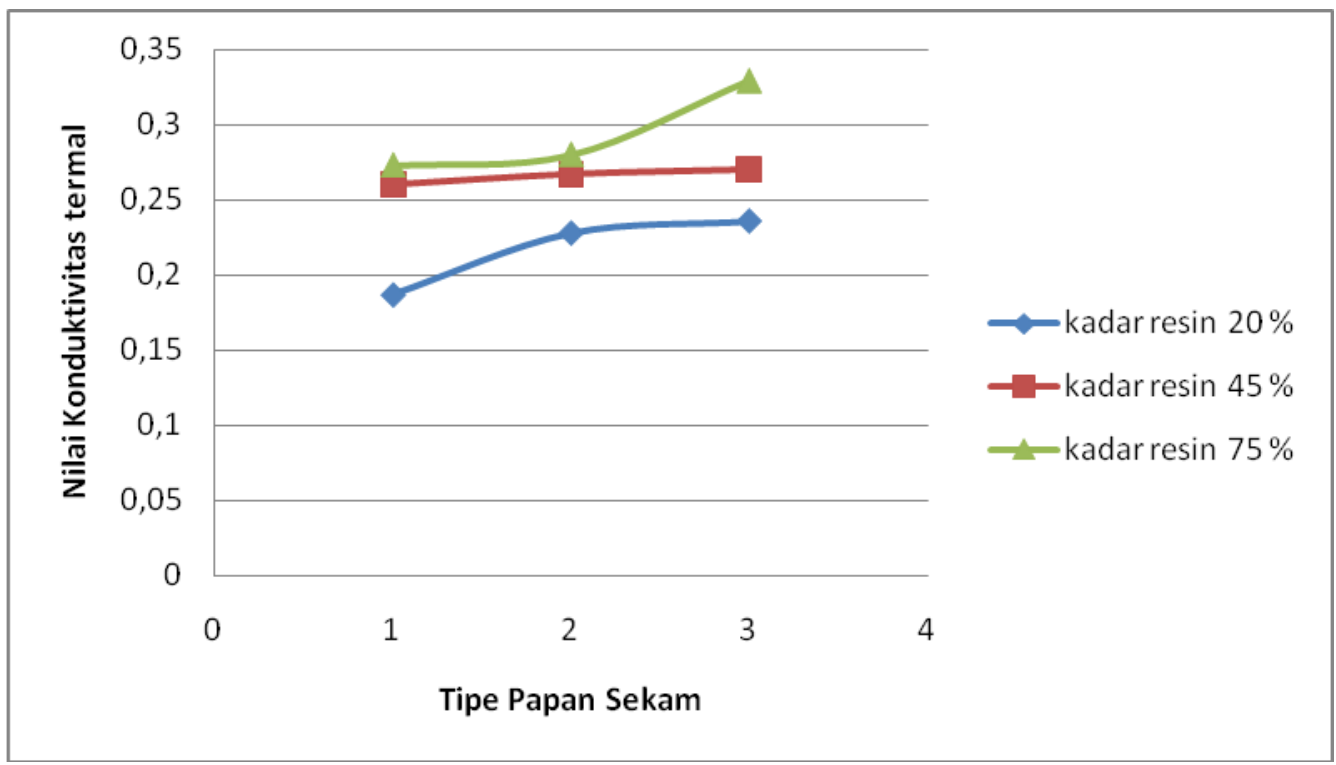

Gambar 2. Grafik pengaruh ukuran sekam terhadap nilai konduktivitas panas papan ( tipe 1 : ukuran sekam $<1 \mathrm{~mm}$, tipe 2 : ukuran sekam $1-2$ $\mathrm{mm}$, tipe 3 : ukuran sekam $>3 \mathrm{~mm}$ )

Pada Gambar 2 terlihat bahwa papan tipe 1 memberikan nilai konduktivitas panas yang paling kecil untuk tiap-tiap kadar resin yang diberikan. Papan tipe 1 merupakan papan dengan ukuran sekam kecil dari $1 \mathrm{~mm}$. Hal ini menunjukkan bahwa papan dengan ukuran sekam lebih kecil memilki sifat isolator yang lebih baik.

Sifat isolator panas dipengaruhi oleh kerapatan partikel penyusun papan. Ukuran sekam yang lebih kecil dapat tersusun lebih rapat dalam papan sekam sehingga meminimalisasi terbentuknya rongga-rongga dalam papan. Rongga-rongga yang terbentuk pada papan akan mengurangi sifat isolator panas papan karena menyebabkan proses konveksi di dalam papan. Untuk bahan konduktor, hal ini akan menyebabkan berkurangnya sifat konduktor papan, sedangkan untuk bahan isolator, rongga-rongga tersebut akan mengurangi sifat isolator bahan

Dari sampel-sampel papan yang teramati terlihat bahwa struktur papan sekam dengan ukuran sekam yang lebih kecil memiliki permukaan yang rata. Selain itu, ukuran sekam yang lebih kecil lebih padu dengan resin dibandingkan dengan ukuran sekam yang lebih besar.

Kadar resin divariasikan untuk tiap-tiap ukuran sekam. Variasi yang diberikan adalah 20 $\%$ untuk papan yang kadar sekamnya lebih dominan, $45 \%$ untuk papan dengan kadar sekamnya berimbang dengan kadar resinnya, $75 \%$ untuk papan dengan kadar resin yang dominan daripada kadar sekamnya. Variasi ini diberikan untuk tiap-tiap ukuran sekam. Nilai konduktivitas untuk tiap-tiap kadar resin ditunjukkan pada Gambar 3.

Gambar 3 memperlihatkan bahwa peningkatan kadar resin membuat nilai konduktivitas panas papan menjadi naik. Pada papan dengan kadar resin yang kecil daripada kadar sekamnya memiliki sifat isolator panas yang lebih baik dibandingkan papan dengan kadar resin yang lebih besar daripada kadar sekamnya . Hal ini menunjukkan bahwa penambahan kadar resin mengurangi sifat isolator papan sekam. 


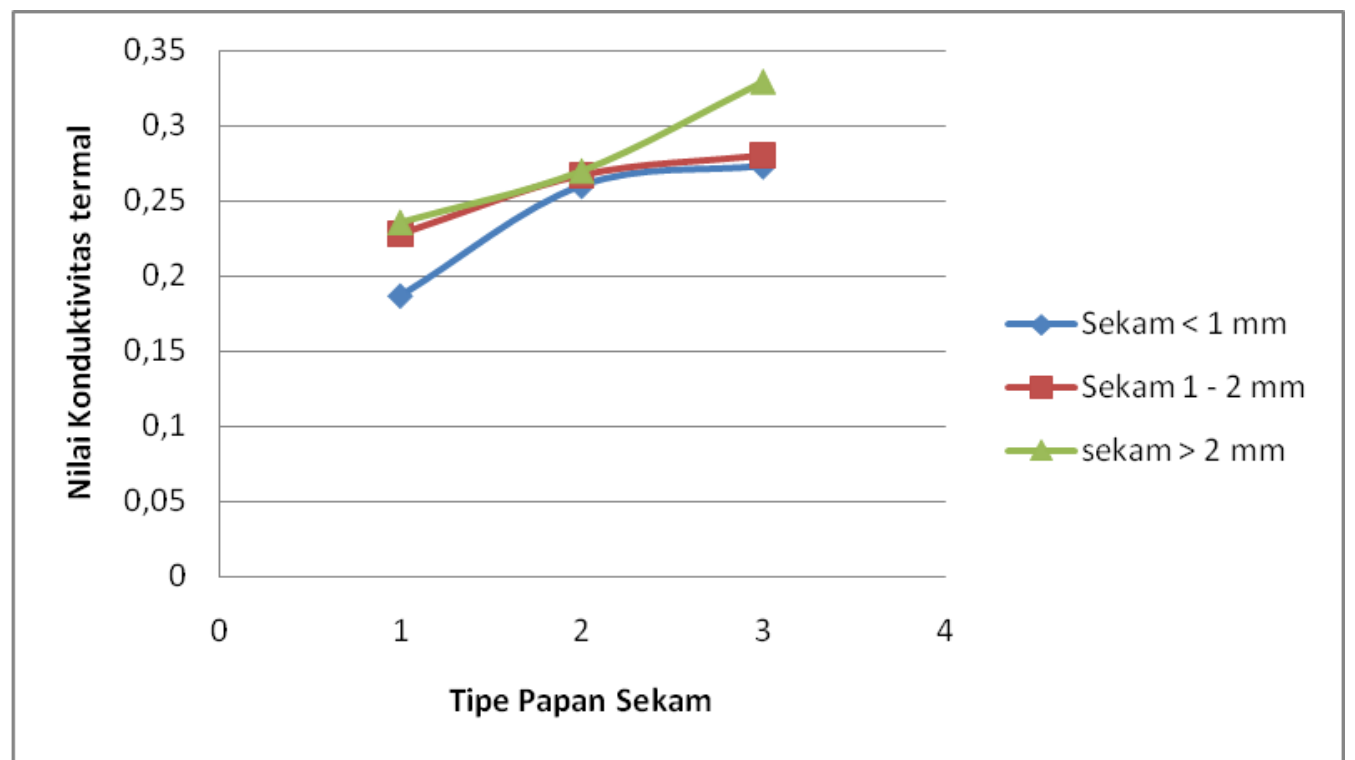

Gambar 3. Grafik pengaruh kadar resin terhadap nilai konduktivitas panas papan sekam ( tipe $1:$ kadar resin $20 \%$, tipe $2:$ kadar resin $45 \%$ dan tipe $3:$ kadar resin $75 \%$ )

Dari sampel-sampel papan yang teramati memperlihatkan bahwa papan dengan kadar resin lebih kecil daripada kadar sekamnya memilki sifat rapuh dan mudah patah. Sedangkan untuk papan dengan kadar resin yang lebih besar dibandingkan kadar sekamnya memilki sifat elastis, kuat dan tidak mudah patah

\section{KESIMPULAN}

Dari hasil penelitian dapat disimpulkan bahwa :

1. Papan sekam dengan diameter sekam kecil dari $1 \mathrm{~mm}$ memiliki sifat isolator panas paling baik dengan nilai konduktivitas yang paling kecil, yaitu $0,187 \mathrm{Js}^{-1} \mathrm{~m}^{-1} \mathrm{~K}^{-1}$

2. Penambahan kadar resin akan menyebabkan penurunan sifat isolator panas pada papan sekam. Hal ini diperlihatkan oleh papan dengan kadar resin $75 \%$ yang memiliki konduktivitas yang paling besar dengan $k=0,329 \mathrm{Js}^{-1} \mathrm{~m}^{-1} \mathrm{~K}^{-1}$

\section{DAFTAR KEPUSTAKAAN}

1. Harsono, Heru, 2002, Pembuatan Silika Amorf dari Limbah Sekam Padi, Jurnal Ilmu Dasar. Universitas Brawijaya.

2. Joelianingsih, 2004, Peningkatan Kualitas Genteng Keramik Dengan Penambahan Sekam Padi dan Daun Bambu, Makalah Pribadi Falsafah Sains (PPS 702), ITB.

3. Wibowo, Hary, Toto Rusianto dan Manarul Ikhsan, 2007, Pengaruh Kepadatan dan Ketebalan Terhadap Sifat IsolatorPanas Papan Partikel Sekam Padi. Yogyakarta : Institut Sains \& Teknologi AKPRIND.

4. www.pustaka-deptan.go.id/bppi/lengkap/sekampadi (diakses desember 2009) 